\title{
Corrigendum
}

\section{Corrigendum to "Statistical Analysis of Influence of Cover Depth on Loess Tunnel Deformation in NW China"}

\author{
Zhao Hu (D), Ke Du, Jinxing Lai $(\mathbb{D}$, and Yongli Xie \\ School of Highway, Chang'an University, Xi'an 710064, China \\ Correspondence should be addressed to Jinxing Lai; laijinxing@chd.edu.cn \\ Received 24 July 2021; Accepted 24 July 2021; Published 12 August 2021 \\ Copyright $\odot 2021$ Zhao Hu et al. This is an open access article distributed under the Creative Commons Attribution License, which \\ permits unrestricted use, distribution, and reproduction in any medium, provided the original work is properly cited.
}

In the article titled "Statistical Analysis of Influence of Cover Depth on Loess Tunnel Deformation in NW China" [1], the authors wish to revise their acknowledgment section as follows:

"This work was financially supported by the Science and Technology Project Plan of Traffic Construction in the West of China (Nos. 2001318000 21, 2007318000 18, and 2014 318 J27 210), the Brainstorm Project on Social Development of Shaanxi Provincial Science and Technology Department (No. 2016SF-412), and National Key R\&D Program of China (No. 2017YFC0805306). The article processing charge was funded by the Fundamental Research Funds for the Central Universities, Chang'an University (No. 300102219716)."

The authors agree to the publication of the corrigendum.

\section{References}

[1] Z. Hu, K. Du, J. Lai, and Y. Xie, "Statistical analysis of influence of cover depth on loess tunnel deformation in NW China," Advances in Civil Engineering, vol. 2019, Article ID 2706976, 12 pages, 2019. 